\title{
Alkali-Activated Binders From Waste Incinerator Bottom Ashes and Metakaolin Reinforced by Recycled Carbon Fiber Composites
}

\author{
Stefania Manzi ${ }^{1 *}$, Isabella Lancellotti ${ }^{2}$, Giulia Masi ${ }^{1}$ and Andrea Saccani ${ }^{1}$ \\ ${ }^{1}$ Department of Civil, Chemical, Environmental and Materials Engineering, University of Bologna, Bologna, Italy, ${ }^{2}$ Department of \\ Engineering "Enzo Ferrari", University of Modena and Reggio Emilia, Modena, Italy
}

\section{OPEN ACCESS}

Edited by:

Patricia Krawczak,

IMT Lille Douai, France

Reviewed by:

Nassim Sebaibi,

École Supérieure d'Ingénieurs des

Travaux de la Construction, France

Girts Bumanis,

Riga Technical University, Latvia

*Correspondence:

Stefania Manzi

stefania.manzi4@unibo.it

Specialty section:

This article was submitted to

Structural Materials,

a section of the journal

Frontiers in Materials

Received: 15 July 2020 Accepted: 06 October 2020 Published: 12 November 2020

Citation:

Manzi S, Lancellotti I, Masi G and Saccani A (2020) Alkali-Activated Binders From Waste Incinerator

Bottom Ashes and Metakaolin

Reinforced by Recycled Carbon

Fiber Composites.

Front. Mater. 7:583400.

doi: 10.3389/fmats.2020.583400
In view of creating low-impact materials for the building industry, the fostering of alkaliactivated binder gains high importance. Metakaolin can successfully be activated with alkalis at room temperature, but the contemporary use of wastes to create mixed binders can further increase the environmental benefits. Bottom ashes obtained from the incineration of municipal solid wastes have been tentatively mixed in different amounts to develop matrix with acceptable mechanical properties, which still can be cured at room temperature. Moreover, scraps obtained from the production of epoxy/carbon fiber composites are employed as a reinforcing phase. No chemical or physical treatments have been used to modify the epoxy/carbon fiber wastes, apart from size reduction, thus minimizing the overall economic and energy impact of the process. The workability, physical and mechanical properties, microstructure, and porosity of the obtained materials are investigated. Up to a 50 weight percent of bottom ashes from municipal solid waste incineration can be mixed with metakaolin. Fibers still embedded in the epoxy matrix disclose a fair interaction with the matrix, thus managing to increase flexural strength, toughness, and dimensional stability without decreasing the compressive strength.

Keywords: building materials, carbon fibers composites wastes, bottom ashes, recycling, alkali-activated materials

\section{INTRODUCTION}

Municipal waste incineration can be used as a waste handling solution. This process can recover energy, exploiting the heat of combustion of the organic fraction of the waste and allows the overall reduction of the volume of wastes, consequently decreasing landfilling depletion. As a drawback, the process itself generates solid wastes, defined as fly ash and bottom ash. Bottom ashes from municipal solid waste incineration have some remarkable characteristics. They contain negligible amounts of toxic elements, have high amorphous fraction, and are largely composed of silica and aluminium oxides. These characteristics have already attracted interest for their use in producing new glass compositions (Saccani et al., 2001) or building materials, especially their pozzolanic activity in traditional Portland cement composites (Saccani et al., 2005; Li et al., 2012; Kuo et al., 2013; Tang et al., 2016; Chen and Yang, 2017; Chen et al., 2019). In recent years, a new class of binders has been investigated, characterized by a lower carbon dioxide footprint than Portland cement, that is, alkaliactivated materials (De Vargas et al., 2011; Sun and Vollpracht, 2019). There are a set of inorganic 
phases showing amorphous or semicrystalline structure formed by a three-dimensional network of $\mathrm{AlO}_{4}$ and $\mathrm{SiO}_{4}$ tetrahedra. They are obtained from a chemical reaction between a binding component (the source of aluminosilicates) and an alkaline activator, usually a blend of caustic alkalis or alkaline salts. For their synthesis, raw materials such as metakaolin, calcined clays, or industrial wastes, such as fly ash or slags, have been used (Boca Santa et al., 2016; Borges et al., 2016; Logesh Kumar and Revathi, 2016; Boca Santa et al., 2017; Bai et al., 2019). Bottom ashes from municipal solid waste incineration can also have an application in these materials because they can be alkali activated when mixed with metakaolin (Lancellotti et al., 2013; Lancellotti et al., 2014; Lancellotti et al., 2015; Silva et al., 2017; Wongsa et al., 2017; Huang et al., 2018). They cannot be used alone as precursor because the amount of $\mathrm{Al}_{2} \mathrm{O}_{3}$ is too low and the higher amount of calcium can change the chemistry of the polymerized network that is formed from alkali activation with the creation of C-A-S-H gels (Borges et al., 2016; Zhu et al., 2018). The alkali activation of this class of materials can take place at different temperatures (Rovnaník, 2010). The most interesting results are obtained from the activation at room temperature (Aredes et al., 2015). Other wastes can be activated only at high temperatures (Sha et al., 2020). It is thus important to verify the mechanical properties of the mixed binders when cured at room temperature.

However, the main problems concerning alkali-activated materials are their complete brittleness and their low dimensional stability. Both defects can be mitigated by modifying the composites through fibers addition, as reported in the literature (Uddin and Shaikh, 2013; Vilaplana et al., 2016; Al-Mashhadani et al., 2018; Bhutta et al., 2018; Luna-Galiano et al., 2018; Akono et al., 2019; Farooq et al., 2019). Waste carbon fibers (CF), embedded in a thermosetting polymer matrix, virtually have high mechanical properties. Either they can be derived from post-user dismissed items or they can be the prepreg offcuts derived from the manufacturing process. Bare fibers can be recovered, eliminating the thermosetting matrix by means of high thermal treatments or selective chemical dissolution. Both the processes imply energy consumption and waste production. The direct use of scraps has been proposed in different matrixes, such as Portland cement, alkali-activated fly ashes, and pure metakaolin. Positive results have been obtained in terms of increased flexural strength and toughness, implying that the presence of a polymeric interphase (epoxy resin) between the fiber and the ceramic matrix still enables a positive interaction between fiber and matrix (Saccani et al., 2019). It seems thus interesting to evaluate the effect of CF/epoxy scraps also in the alkali-activated systems where metakaolin is partially substituted by bottom ashes from municipal solid waste incineration. The mix design has been investigated focusing on the workability of fresh mixtures, microstructure (i.e., fibers dispersion and porosity), flexural strength, and toughness. A room temperature curing has been studied, being the lowest energyconsuming treatment. In case these materials should prove to have acceptable mechanical properties, which is the main scope of the research, they could provide potentially high environmental benefit because they could enable the simultaneous recycling of

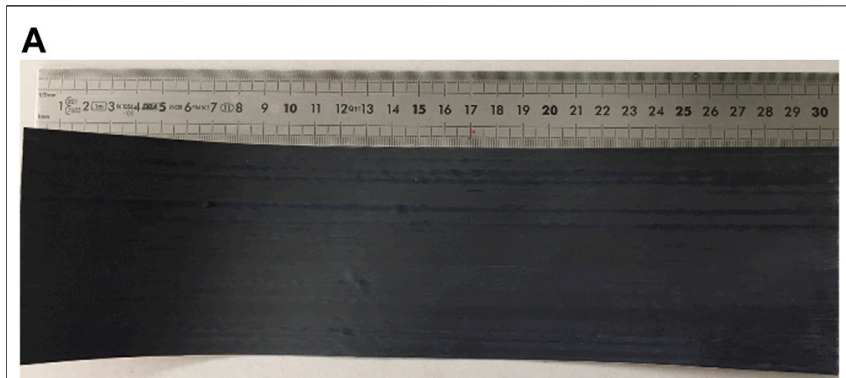

B

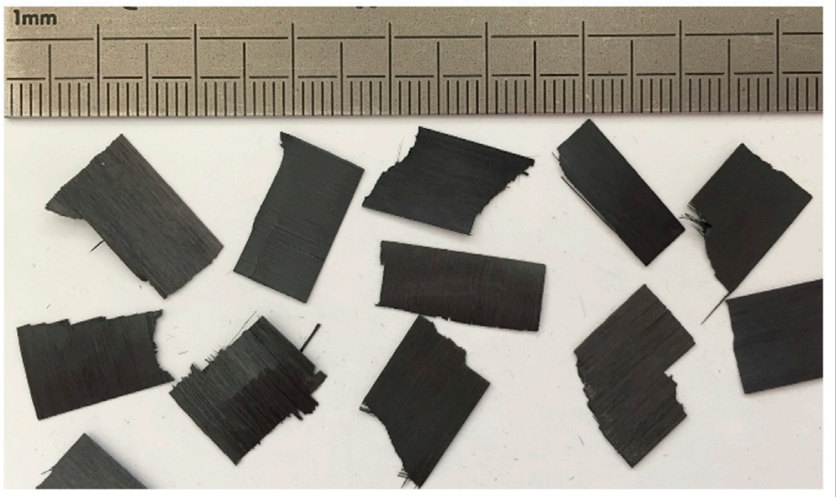

FIGURE 1 | (A) Full view of composite pre-pregs scraps. (B) Micrograph of the shredded multi layers.

TABLE 1 | Composition of the raw materials (wt\%).

\begin{tabular}{|c|c|c|c|c|c|c|c|c|c|c|}
\hline Material & $\mathrm{SiO}_{2}$ & $\mathrm{Al}_{2} \mathrm{O}_{3}$ & $\mathrm{Na}_{2} \mathrm{O}$ & $\mathrm{K}_{2} \mathrm{O}$ & $\mathrm{CaO}$ & $\mathrm{MgO}$ & $\mathrm{Fe}_{2} \mathrm{O}_{3}$ & $\mathrm{TiO}_{2}$ & MnO & LOI \\
\hline Metakaolin & 53.5 & 41.9 & 0.0 & 2.6 & 0.0 & 0.0 & 1.4 & 0.6 & 0.0 & 0.0 \\
\hline $\begin{array}{l}\text { Bottom } \\
\text { ash }\end{array}$ & 49.5 & 9.4 & 5.7 & 1.4 & 17.5 & 2.9 & 4.9 & 0.9 & 0.2 & 4.9 \\
\hline
\end{tabular}

different wastes, reducing the amount of metakaolin and virgin carbon fibers to be used. The first issue eliminates the thermal treatments of aluminosilicate precursor that are necessary, thus avoiding $\mathrm{CO}_{2}$ emissions, and the second one would prevent scrap damping and avoid virgin fiber production. Indeed, the complete life cycle assessment of the derived material should be carried out, a process that is however beyond the aims of this study that merely faces the technical problems related to the material performance upon modification.

\section{EXPERIMENTAL}

\section{Composites Waste Scraps}

Pre-preg offcuts derived from the production of CF/epoxy (hereafter defined as W_CF/EP) composites have been used. The as-received scraps had an almost rectangular shape with side dimension ranging from 10 to $40 \mathrm{~cm}$ (Figure 1A shows an example). They were made of multiple CF/epoxy impregnated layers with an average thickness ranging from 150 to $450 \mu \mathrm{m}$. 
TABLE 2 | Formulation of composites.

\begin{tabular}{|c|c|c|c|c|c|c|}
\hline Sample & Metakaolin (g) & BA (g) & NaOH 8M (ml) & $\mathrm{Na}_{2} \mathrm{SiO}_{3}(\mathrm{ml})$ & W_CF/EP (g) & $\mathbf{w} / \mathbf{b}$ ratio \\
\hline BA25-W_CF/EPO & 75 & 25 & 25 & 60 & 0 & 0.36 \\
\hline BA25-W_CF/EP3 & 75 & 25 & 25 & 60 & 3 & 0.36 \\
\hline BA25-W_CF/EP6 & 75 & 25 & 25 & 60 & 6 & 0.36 \\
\hline BA25-W_CF/EP9 & 75 & 25 & 25 & 60 & 9 & 0.36 \\
\hline BA25-W_CF/EP12 & 75 & 25 & 25 & 60 & 12 & 0.36 \\
\hline BA50-W_CF/EP0 & 50 & 50 & 16 & 40 & 0 & 0.28 \\
\hline BA50-W_CF/EP3 & 50 & 50 & 16 & 40 & 3 & 0.28 \\
\hline BA50-W_CF/EP6 & 50 & 50 & 16 & 40 & 6 & 0.28 \\
\hline BA50-W_CF/EP9 & 50 & 50 & 16 & 40 & 9 & 0.28 \\
\hline BA50-W_CF/EP12 & 50 & 50 & 16 & 40 & 12 & 0.28 \\
\hline
\end{tabular}

BA, bottom ash; CF, waste carbon fibers; W_CF/EP, pre-preg offcuts derived from the production of CF/epoxy; w/b ratio: water/binder ratio.

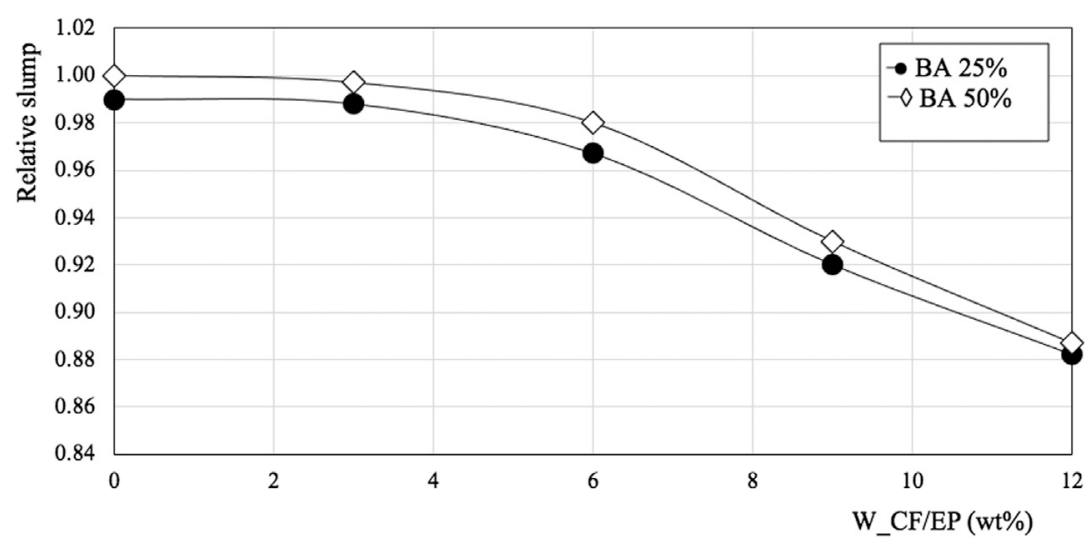

FIGURE 2 | Relative workability of the investigated composites.

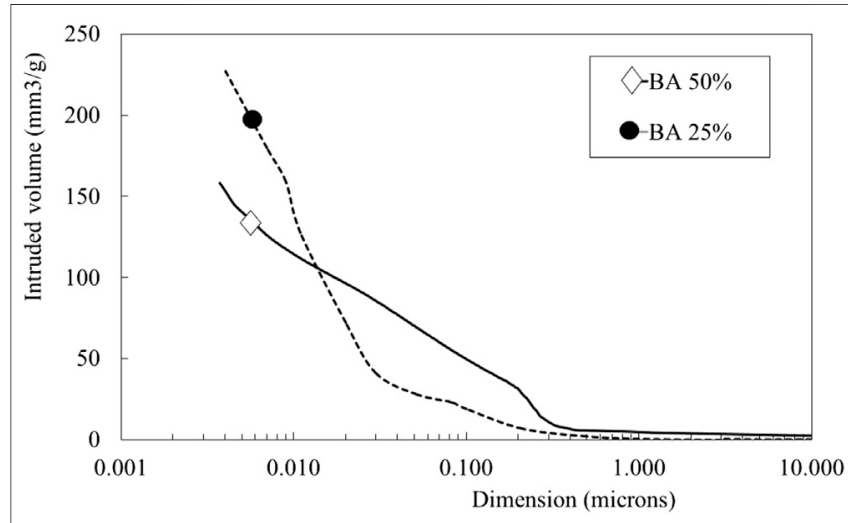

FIGURE 3 | Cumulative intruded volume in the plain matrices.

The original multiple layer sheets were treated for $1 \mathrm{~h}$ at $130^{\circ} \mathrm{C}$ to complete the cross-linking reactions and then cut to obtain fibers bundles with the length of $13 \pm 2 \mathrm{~mm}$ and lateral size ranging from 5 to $10 \mathrm{~mm}$ (Figure 1B). The amount of resin that surrounds the carbon fibers was evaluated by weight loss through the use of a TGA instrument (Thermogravimetric Analysis, Q50 Model TA Instruments) and was estimated as a $30 \pm 8 \mathrm{wt} \%$.

\section{Binders}

Metakaolin with a dimension lower than $75 \mu \mathrm{m}$ was used as binder. Bottom ashes from municipal waste incineration, hereafter simply defined as BA, once collected by the company managing the disposal of ashes from different incinerator plants are submitted to beneficiation. The process involves ageing, grinding, and $\mathrm{Fe}$ and $\mathrm{Al}$ separation by means of magnetic and eddy current systems. After these treatments, BA are no more classified as waste according to the European Waste Code, but as secondary raw materials (end of waste). Final product was ballmilled and sieved through a $100 \mu \mathrm{m}$ sieve to favor their homogeneous mixing with metakaolin and subsequent reactions. In details, metakaolin powders show the following parameters: $\mathrm{D}_{10}=1.40, \mathrm{D}_{50}=11.08$, and $\mathrm{D}_{90}=50.98$. For $\mathrm{BA}$ the values are as follows: $\mathrm{D}_{10}=1.81, \mathrm{D}_{50}=21.53$, and $\mathrm{D}_{90}=61.71$. Data have been derived by laser particle sizer Fritsch, Analysette 22. Table 1 reports the chemical composition of both metakaolin and BA as derived by X-ray fluorescence (Philips PW 2004). Other detected elements, such as sulphur, phosphor, and chlorine, are not reported. Loss on ignition was determined after a $2 \mathrm{~h}$ treatment at $1,100^{\circ} \mathrm{C}$. X-ray analysis was performed in order to evaluate the amorphous or crystalline nature of BA and to identify the crystalline phases present. From the analysis (not reported for briefness sake), the typical amorphous/ 
TABLE 3 | Classification of porosity in the investigated samples according to IUPAC.

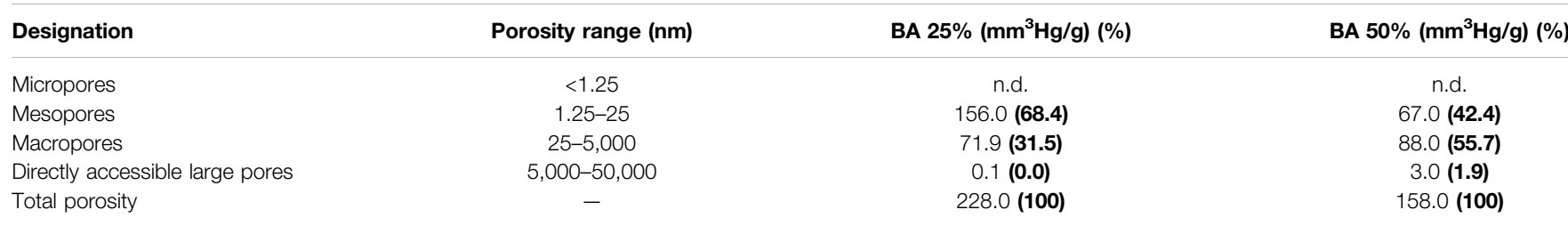

Pore size classification (percentage of porosity over the total specific volume of $\mathrm{Hg}$ is reported in brackets).

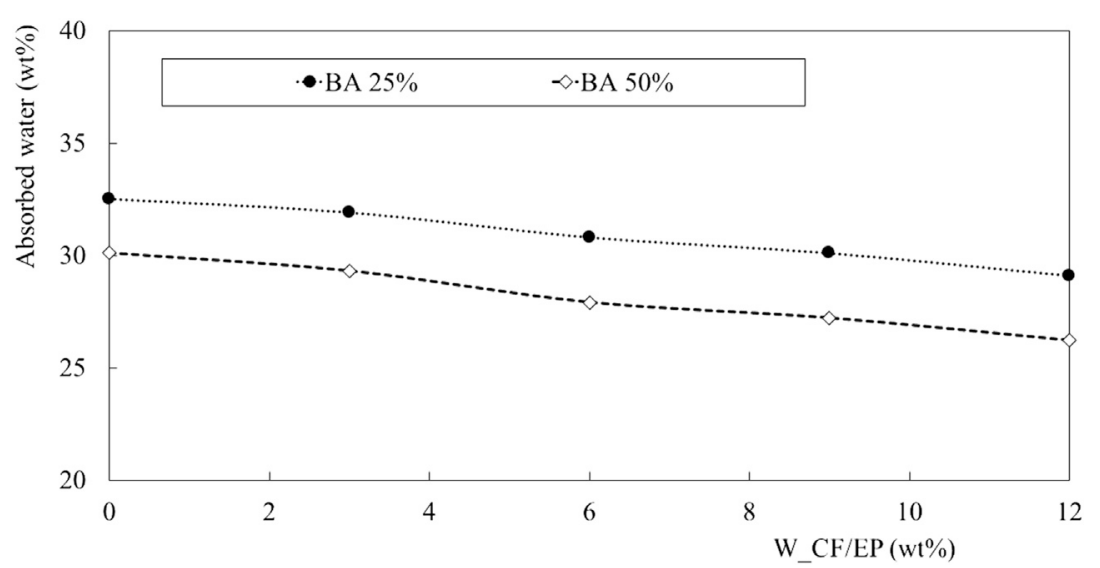

FIGURE 4 | Water absorption of all the investigated samples.

crystalline nature of the material is determined. Among the crystalline fraction, the main detected phase is a-quartz $\left(\alpha-\mathrm{SiO}_{2}\right.$, JCPDF file 33-1161) followed by calcite (CaCO3 JCPDF file 5-586), and aluminosilicates as albite $\left(\mathrm{NaAlSi}_{3} \mathrm{O}_{8}\right.$ JCPDF file 10-393) and ghelenite $\left(\mathrm{Ca}_{2} \mathrm{Al}(\mathrm{Al}, \mathrm{Si}) \mathrm{O}_{7}\right.$ JCPDF file 35-755), thus reflecting the chemical analysis of a typical ash rich in calcium and sodium.

\section{Activators}

Sodium hydroxide reagent grade and sodium silicate solution, a viscous liquid produced for the cement industry with a water content of $57 \mathrm{wt} \%$ and $\mathrm{SiO}_{2} / \mathrm{Na}_{2} \mathrm{O}$ ratio of 3 , were used as alkaline activators.

\section{Mixing Procedures and Compositions}

Sodium hydroxide $8 \mathrm{M}$ solution and sodium silicate have been first mixed according to the quantities determined in previous experiments (Lancellotti et al., 2013; Lancellotti et al., 2014). The quantities added aimed primarily to obtain equal workability. Moreover, due to the higher content of $\mathrm{Na}$ in $\mathrm{BA}$, less amount of sodium hydroxide and silicate are added. On account of the higher ratio of $\mathrm{SiO}_{2} / \mathrm{Al}_{2} \mathrm{O}_{3}$ in $\mathrm{BA}$, less silicate is added (Table 1). Afterward, metakaolin mixed with the different quantity of BA (25 or $50 \mathrm{wt} \%$ ) was added. The workability was determined through the minislump test proposed by EN-ETC. No additional water has been added to the fiber-modified materials and consequently workability decreased as the amount of $\mathrm{W}_{-} \mathrm{CF} / \mathrm{EP}$ increased. However, up to the highest investigated quantity, it was still possible to effectively fill the moulds without creating macro-voids. W_CF/EP amounts were 3, 6, 9, and $12 \mathrm{wt} \%$ on the powders. Table 2 reports the mix design of the investigated materials. The dimension of the prepared samples during casting procedures was different on the basis of further characterizations. Prisms of $100 \mathrm{~mm} \times 20 \mathrm{~mm} \times 20 \mathrm{~mm}$ size were cast (nine for each composite composition) and cured for 28 days at $25 \pm 1{ }^{\circ} \mathrm{C}$ and $98 \pm 1 \%$ relative humidity. Prisms of $250 \mathrm{~mm} \times 25 \mathrm{~mm} \times 25 \mathrm{~mm}$ were used to investigate the freedrying shrinkage $v s$ time when samples were cured at $25^{\circ} \mathrm{C}$ and $35 \pm 5 \%$ relative humidity.

\section{Tests and Procedures Water Absorption and Porosity}

Water absorption has been evaluated according to the UNI 7699 Standard (UNI 7699, 2005) on three samples $(100 \mathrm{~mm} \times 20 \mathrm{~mm}$ $\times 20 \mathrm{~mm}$ ) cured for 28 days. The cumulative open porosity and the size distribution of the porosities in samples without fibers (i.e., the plain matrixes formulated with 25 and $50 \mathrm{wt} \%$ of BA but without the fibers) have been evaluated by mercury intrusion porosimetry (MIP) equipped with a macropore unit (Thermo Scientific, Pascal 140 and 240). Measurements were conducted at 28 days of curing. MIP measurements performed on composite samples were not reliable or reproducible because of the small dimension of the tested specimens allowed and the unavoidable damage induced by specimen size reduction. Accordingly, they will not be reported. 


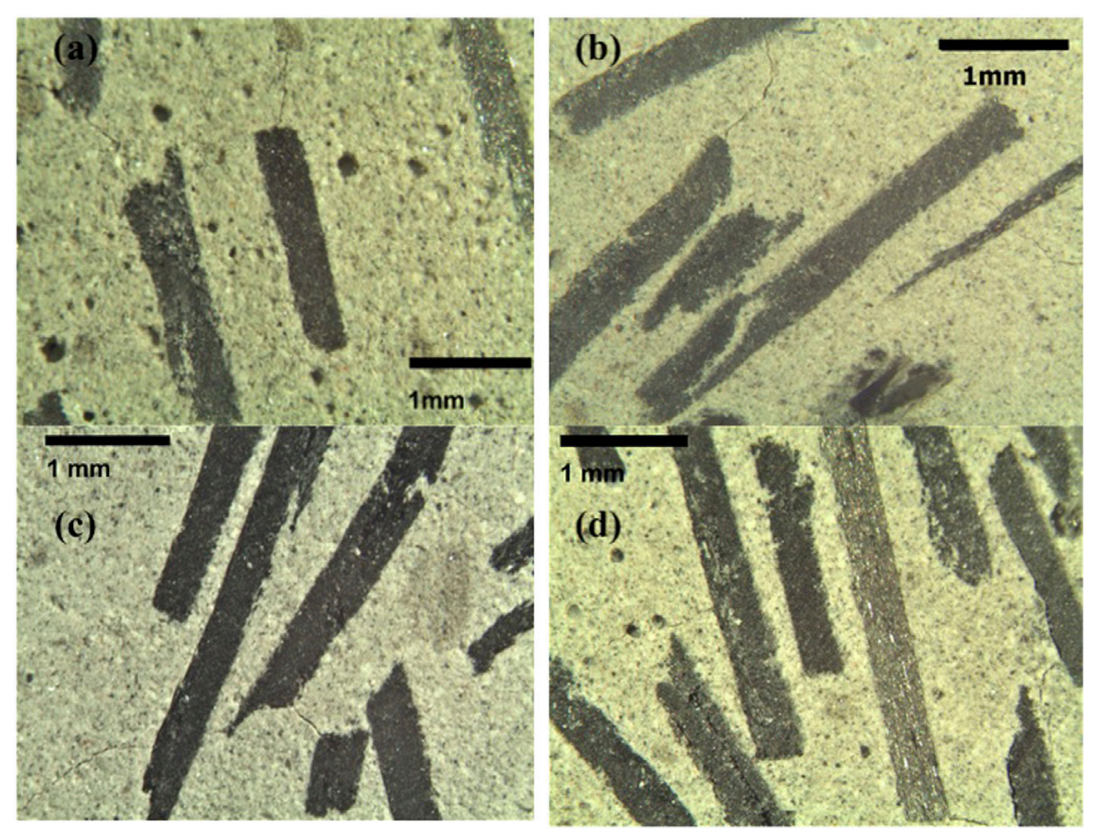

FIGURE 5 | Optical micrograph of BA25-W_CF/EP samples cross sections at 3 (A), 6 (B), 9 (C), and 12 (D) wt. amount of fibers at 20×.

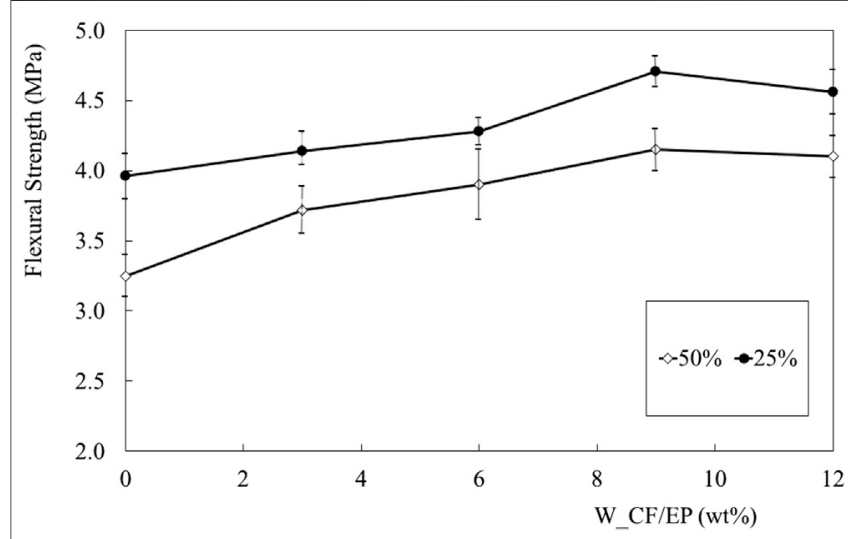

FIGURE 6 | Flexural strength of the investigated materials.

\section{Mechanical Tests}

Mechanical tests (three-point bending) were performed at room temperature with a relative humidity of $50 \pm 10 \%$ by means of $100 \mathrm{kN}$ Amsler Wolpert equipment, with a $5 \mathrm{~mm} / \mathrm{min}$ displacement rate. Flexural strength values are reported as the average of six measurements. Compressive strength measurement was performed on both the prisms derived from the previous flexural test (12 measurements).

\section{SEM Analysis}

Morphological investigations were carried out on fractured surfaces of mortar samples sputtered by graphite by means of

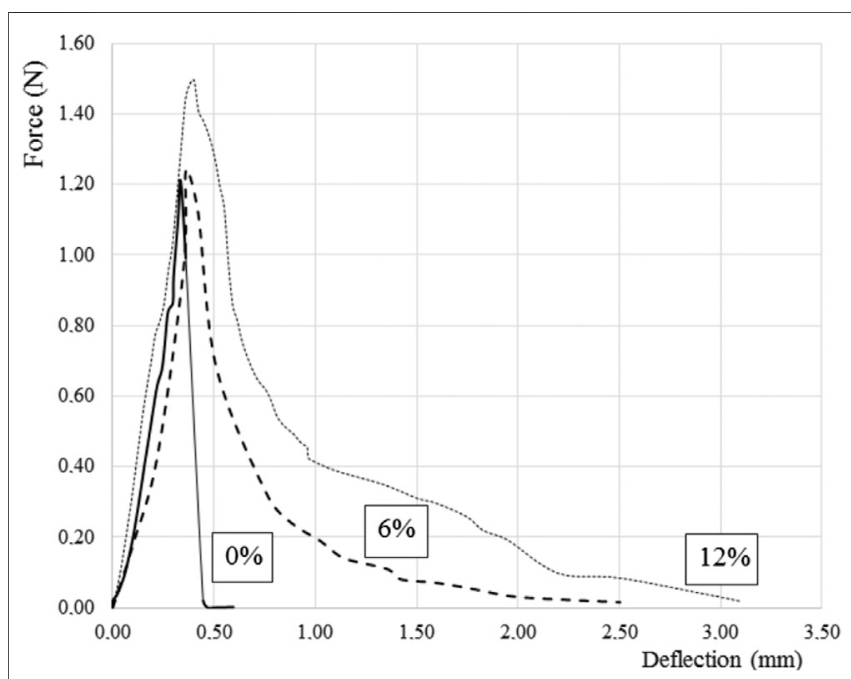

FIGURE 7 | Force $v$ s deflection plot of specimens containing $50 \%$ of BA at different amounts of W_CF/EP.

electron scanning microscopy (ESEM, Quanta-200, FEI Co.), exploiting the signal collected by secondary electrons detectors. An accelerating voltage of $20 \mathrm{kV}$ was applied.

\section{Dimensional Stability}

Dimensional stability has been evaluated according to the ASTM C1012/C1012M standards (ASTM C1012/C1012M, 2015) on three prismatic specimens of $250 \mathrm{~mm} \times 25 \mathrm{~mm} \times 25 \mathrm{~mm}$ cured at $25^{\circ} \mathrm{C}$ and $35 \pm 5 \%$ relative humidity. 


\section{RESULTS}

Figure 2 shows the relative workability of samples containing the different amounts of recycled composites, as well as the different amounts of BA. Standard deviations are not included for the sake of clearness because they almost coincide with the dimension of the symbols. While the effect of the different amounts of BA is negligible as desired, W_CF/EP addition progressively decreases this property. However, as underlined before, all mixtures could be easily cast without the formation of macrovoids. The decrease is partially related to the amount of water requested to wet the reinforcement surfaces. Although the composites scraps are no more flexible after the full-cross-

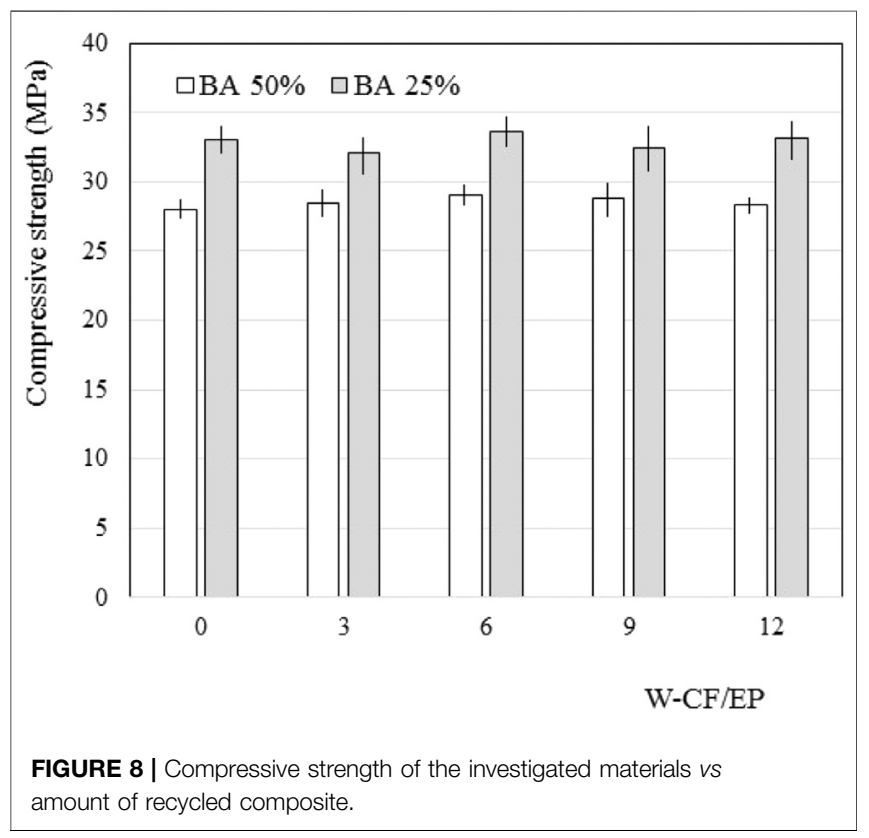

linking reaction, their small dimension prevents buckling phenomena.

Figure 3 shows the results of MIP analysis: the total intruded volume in the two different plain matrices is reported $v s$ the pore dimension. The sample containing the lower amount of BA (25\%) shows the highest overall porosity $\left(228 \mathrm{~mm}^{3} / \mathrm{g}\right.$ of intruded volume), with almost half of the pores having dimensions lower than $0.01 \mu \mathrm{m}$. BA $50 \%$ matrix shows a lower overall porosity $\left(158 \mathrm{~mm}^{3} / \mathrm{g}\right.$ of intruded volume), but the dimension of the pores is larger than that in the previous sample, mainly falling in the range from 0.4 to $0.01 \mu \mathrm{m}$. To get a detailed analysis of the results, Table 3 reports the amount of pores divided in different ranges proposed by the IUPAC classification. The main differences are related to the mesopores and macropores that suggest similar observations as those previously proposed. In the BA $25 \%$ sample, no large pores $(>5,000 \mathrm{~nm})$ are detected, and the amount is quite limited in the BA $50 \%$ sample.

This can be explained by assuming that, in the applied curing conditions, the reactions involving the BA fraction are slower than those involving metakaolin, thus producing a lower amount of binding products or polymerized network only partially filling the larger voids, as found in other researches (Guo et al., 2017; Sha et al., 2020). Moreover, the presence of C-S-A-H product can change the porosity of the products. Consequently, although the $\mathrm{w} / \mathrm{b}$ ratio in the BA $50 \%$ sample is lower, the capillary porosity is increased.

Figure 4 reports the water absorption of all the samples after 28 days of curing. The higher amount of BA slightly decreases the amount of absorbed water. Moreover, as the amount of recycled composite increases, values tend to decrease slightly at both the BA amounts. The percentage of absorbed water is usually linked to the overall volume of open porosity in the material. This result is also in accordance with the previous observation on the absence of large voids caused by the workability reduction. Moreover, as the amount of absorbed water progressively decreases, there is absence of a discontinuity

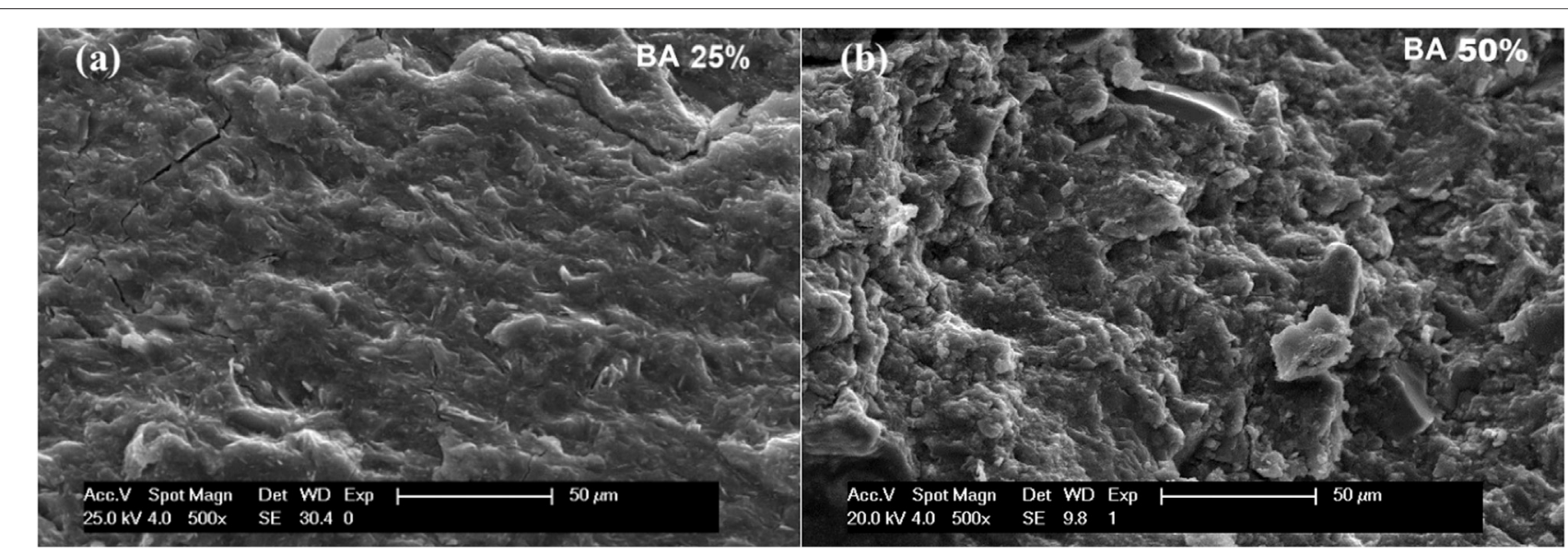

FIGURE 9 | Microstructure of (A) BA25-W_CF/EP0 and (B) BA50-W_CF/EP0 (fracture surfaces). 


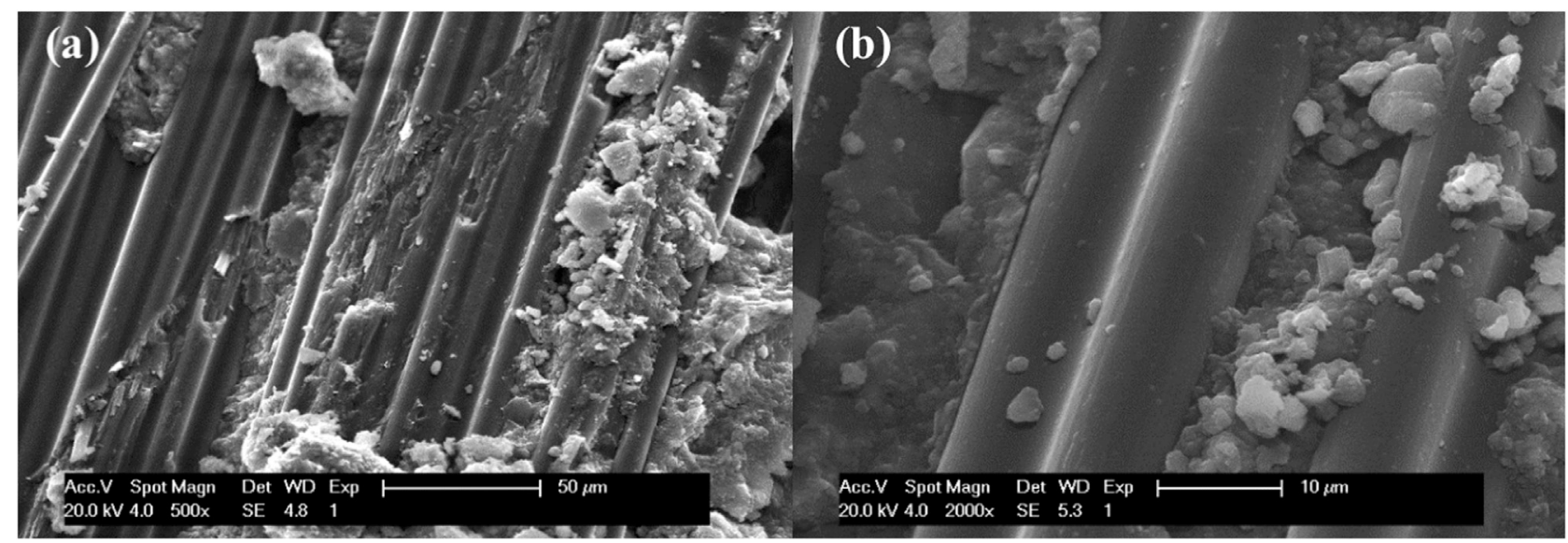

FIGURE 10 | Fracture surface of (A) BA25-W_CF/EP6 and (B) BA50-W_CF/EP6.

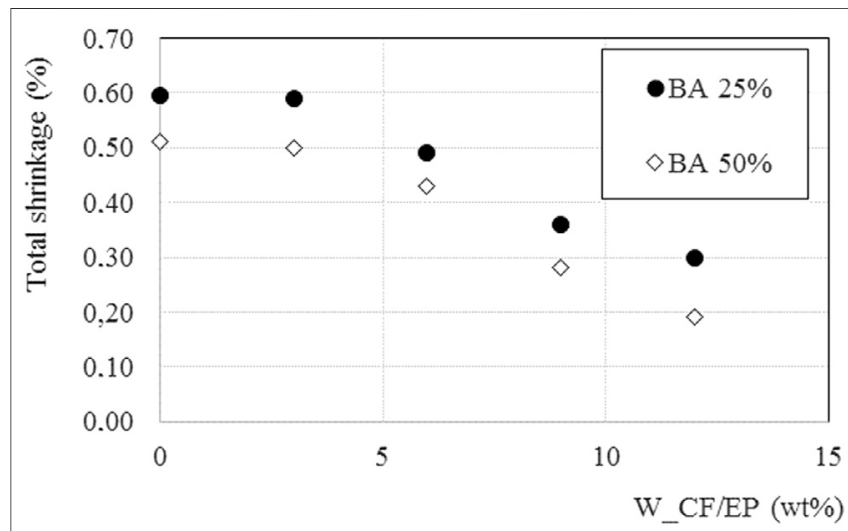

FIGURE 11 |Dimensional changes for samples cured at $35 \pm 5 \%$ relative humidity.

between the waste and the matrix, suggesting an efficient adhesion between the different phases and the creation of a continuous interface transition zone between the cured epoxy and the ceramic matrix that can promote the increase in mechanical properties. The positive interaction is related to the presence of dipoles formed by $\mathrm{C}-\mathrm{O}$ bonds in the resin interacting with ceramic matrix. The slight decrease in BA $50 \%$ compared with BA $25 \%$ can be explained considering the different total porosity of the two matrixes found by MIP analysis as observed in Figure 3. The same observation can explain the progressive reduction in the absorbed water as the amount of W_CF/EP increases. Indeed, a partial substitution of the porous phase, the matrix, with a non-porous fraction, the organic composite, takes place, decreasing the overall fraction of porosities.

The severed surfaces obtained by diamond sawing of the different samples (Figures 5A-D) again underline the absence of large voids ( $>1 \mathrm{~mm}$ ) derived from insufficient workability, as was expected by visual inspection during casting operations. No differences at this magnification were found between the different amounts of BA and consequently only $25 \mathrm{wt} \%$ BA loading is reported. No clusters of fibers were also visible from the Figures, implying that an efficient dispersion is obtained.

Figure 6 shows the flexural strength of the composites at 28 days of curing. As it can be observed, the increase in the amount of BA, from 25 to $50 \mathrm{wt} \%$, decreases the mechanical properties of the composites. This is probably related to the presence, in the $50 \%$ samples, of a higher amount of porosities in the range from 0.02 to $0.4 \mu \mathrm{m}$ with respect to the $25 \% \mathrm{BA}$ composition as observed from the MIP measurements. This difference is possibly derived, as explained before, from the different reaction products generated (i.e., from the presence of C-A-S-H products) and also from the different kinetics of the binding reactions involving metakaolin and BA. However, the addition of W_CF/EP almost linearly increases the flexural strength of all the samples, confirming the positive effect of the fibers.

Figure 7 shows the plots reporting the force $v s$ the deflection of all samples containing $50 \%$ of BA. For sake of brevity, only this set of specimens is reported. Along with the increase in flexural strength already discussed, a progressive increase in toughness takes place. In fiber-modified samples instead of one crack leading to the almost instantaneous overall fracture, a web of small cracks is formed leading to a postponed failure. Consequently, as the fully brittle behavior of the unmodified matrix is changed, higher amounts of energy can be absorbed as the amount of recycled composite increases. The mechanism supporting this effect is related to the progressive pull-out of the fibers from the matrix. The toughening effect of the fibers is reflected by the increase in the area beneath the plot.

Figure 8 reports the values of compressive strength of the investigated materials. This property is almost unaffected by the waste addition, both W_CP/EP and BA. Only at the highest amount of fibers, a slight reduction is found in samples, whereas at the lowest amounts, compressive strength slightly increases. Larger increases in compressive strength were found in other 
researches, although with different conditions (Uddin and Shaikh, 2013; Bhutta et al., 2018).

The SEM analysis of mortars without W_CF/EP at different BA amounts is reported in Figure 9. Both the matrixes appear as compact without porosities. In the $50 \% \mathrm{BA}$ matrix, some unreacted BA particles still showing sharp edges are visible. This confirms that at room temperature, the reactions leading to the geopolymerization of at least one fraction of $\mathrm{BA}$ are rather slow as previously observed (Uddin and Shaikh, 2013; Bhutta et al., 2018). Figure 10 reports the morphology of the fractured surfaces derived from the flexural tests of samples modified with W_CF/EP. Some matrix particles adhere to the fibers, and no porosities are present at the interphase between matrix and wastes. This implies a fair interaction of the filler with the matrix, supporting the previous observations related to the amounts of absorbed water.

Indeed, it should also be underlined that no remarkable qualitative differences can be observed on changing the amount of BA in the matrix. Eventually, Figure 11 reports the dimensional changes at 14 days for samples cured at $35 \pm 5 \%$ relative humidity. A slight increase in the dimensional shrinkage of sample BA25-W_CF/EP can be observed when compared with BA50-W_CF/EP, probably on account of the overall higher porosity. Samples containing 3\% of W_CF/EP show almost the same behavior as the unmodified matrixes, but further additions progressively increase the dimensional stability of the composites, an effect that has been found in conventional Portland cement materials by adding recycled carbon fibers (Wang et al., 2019).

It is important to underline from the results so far obtained that wastes derived from composite manufacturing can be recycled in the production of building materials without previous chemical or thermal treatments. The scraps can improve the mechanical behavior of metakaolin materials geopolymerized at low temperature. In this way, the use of low-energy consuming, low-impact products, where an economical value-added benefit is also achieved, can be successfully promoted.

\section{CONCLUSIONS}

The results of this research can thus be summarized as follows:

\section{REFERENCES}

Akono, A. T., Koric, S., and Kriven, W. M. (2019). Influence of pore structure on the strength behavior of particle and fiber-reinforced metakaolin-based geopolymer composites. Cem. Concr. Comp. 104, 103361. doi:10.1016/j. cemconcomp.2019.103361

Al-Mashhadani, M., Canpolat, O., Aygörmez, Y., Uysal, M., and Erdem, S. (2018). Mechanical and microstructural characterization of fiber reinforced fly ash based geopolymer composites. Constr. Build. Mater. 167, 505-513. doi:10.1016/ j.conbuildmat.2018.02.061

Aredes, F. G. M., Campos, T. M. B., Machado, J. P. B., Sakane, K. K., Thim, G. P., and Brunelli, D. D. (2015). Effect of cure temperature on the formation of metakaolinite-based geopolymer. Ceram. Int. 41, 7302-7311. doi:10.1016/j. ceramint.2015.02.022

ASTM C1012/C1012M (2015). Standard test method for length change of hydraulic-cement mortars exposed to a sulfate solution, West Conshohocken, PA: ASTM International, 19428-2959.
- Metakaolin can be mixed with BA up to an amount of $50 \mathrm{wt}$ $\%$. The binder can still be activated at room temperature still showing even at the highest amount of BA, acceptable mechanical strengths.

- Untreated wastes derived from the production of carbon fiber epoxy composites have been homogeneously dispersed to formulate composites up to 12 weight $\%$. Although the workability of the fresh mixtures decreases as the amount of waste increases, it is possible to cast mortars without highdimension porosities. Microstructural analysis discloses a fair interaction between the fibers still surrounded by the epoxy coating and the matrix.

- CF/epoxy wastes increase the flexural strength of all the composites and drive their fracture from a brittle behaviour to a semiductile one. The compressive strength is practically unaffected by carbon fibers addition. Moreover, the addition of the fibrous wastes increases the dimensional stability of the composites.

\section{DATA AVAILABILITY STATEMENT}

All datasets presented in this study are included in the article.

\section{AUTHOR CONTRIBUTIONS}

SM: conceptualization, methodology, validation, investigation, resources, data curation, visualization, writing original draft preparation, and editing. IL: methodology, validation, and resources. GM: investigation, data curation, and visualization. AS: conceptualization, methodology, validation, investigation, resources, data curation, visualization, writing original draft preparation and editing, and supervision.

\section{ACKNOWLEDGMENTS}

The authors acknowledge the support of Lorenzo Lipparini (REGLASS) for providing CF/EP composites.

Bai, T., Song, Z., Wang, H., Wu, Y., and Huang, W. (2019). Performance evaluation of metakaolin geopolymer modified by different solid wastes. J. Clean. Prod. 226, 114-121. doi:10.1016/j.jclepro.2019.04.093

Bhutta, A., Farooq, M., and Banthia, N. (2018). Matrix hybridization using waste fuel ash and slag in alkali-activated composites and its influence on maturity of fibre-matrix bond. J. Clean. Prod. 177, 857-867. doi:10.1016/j.jclepro.2018.01. 001

Boca Santa, R. A. A., Soares, C., and Gracher Riella, H. (2016). Geopolymers with a high percentage of bottom ash for solidification/immobilization of different toxic metals. J. Hazard. Mater. 318, 145-153. doi:10.1016/j.jhazmat. 2016.06.059

Boca Santa, R. A. A., Soares, C., and Gracher Riella, H. (2017). Geopolymers obtained from bottom ash as source of aluminosilicate cured at room temperature. Constr. Build. Mat. 157, 459-466. doi:10.1016/j.conbuildmat.2017.09.111

Borges, P. H. R., Banthia, N., Alcamand, H. A., Vasconcelos, W. L., and Nunes, E. H. M. (2016). Performance of blended metakaolin/blastfurnace slag alkaliactivated mortars. Cem. Concr. Comp. 71, 42-52. doi:10.1016/j.cemconcomp. 2016.04.008 
Chen, P., Feng, B., Lin, Y., and Lin, C. (2019). Solidification and stabilization of sewage sludge and MSWI bottom ash for beneficial use as construction materials. J. Mater. Civ. Eng. 31(1), 04018351. doi:10.1061/(ASCE)MT.19435533.0002572

Chen, Z., and Yang, E. (2017). Early age hydration of blended cement with different size fractions of municipal solid waste incineration bottom ash. Constr. Build. Mater. 15, 880-890. doi:10.1016/j.conbuildmat.2017.09.063

De Vargas, A. S., Dal Molin, D. C. C., Vilela, A. C. F., da Silva, F. J., Pavão, B., and Veit, H. (2011). The effects of $\mathrm{Na}_{2} \mathrm{O} / \mathrm{SiO}_{2}$ molar ratio, curing temperature and age on compressive strength, morphology and microstructure of alkaliactivated fly ash-based geopolymers. Cem. Concr. Comp. 33(6), 653-660. doi:10.1016/j.cemconcomp.2011.03.006

Farooq, M., Bhutta, A., and Banthia, N. (2019). Tensile performance of eco-friendly ductile geopolymer composites (EDGC) incorporating different micro-fibers. Cem. Concr. Comp. 103, 183-192. doi:10.1016/j.cemconcomp.2019.05.004

Guo, X., Shi, H., and Wei, X. (2017). Pore properties, inner chemical environment, and microstructure of nano-modified CFA-WBP (class $\mathrm{C}$ fly ash-waste brick powder) based geopolymers. Cem. Concr. Comp. 79, 53-61. doi:10.1016/j. cemconcomp.2017.01.007

Huang, G., Ji, Y., Li, J., Hou, Z., and Jin, C. (2018). Use of slaked lime and Portland cement to improve the resistance of MSWI bottom ash-GBFS geopolymer concrete against carbonation. Constr. Build. Mater. 166, 290-300. doi:10.1016/j. conbuildmat.2018.01.089

Kuo, W. T., Liu, C. C., and Su, D. S. (2013). Use of washed municipal solid waste incinerator bottom ash in pervious concrete. Cem. Concr. Comp. 37 (1), 328-335. doi:10.1016/j.cemconcomp.2013.01.001

Lancellotti, I., Cannio, M., Bollino, F., Catauro, M., and Leonelli, C. (2015). Geopolymers: an option for the valorization of incinerator bottom ash derived "end of waste". Ceram. Int. 41, 2116-2123. doi:10.1016/j.ceramint.2014.10.008

Lancellotti, I., Ponzoni, C., Barbieri, L., and Leonelli, C. (2013). Alkali activation processes for incinerator residues management. Waste Manag. 33, 1740-1749. doi:10.1016/j.wasman.2013.04.013

Lancellotti, I., Ponzoni, C., Bignozzi, M., Barbieri, L., and Leonelli, C. (2014). Incinerator BA and Ladle slag for geopolymers preparation. Waste Bio.Valor. 5, 393-401. doi:10.1007/s12649-014-9299-2

Li, X., Lv, Y., Ma, B., Chen, Q., Yin, X., and Jian, S. (2012). Utilization of municipal solid waste incineration bottom ash in blended cement. J. Clean. Prod. 32, 96-100. doi:10.1016/j.jclepro.2012.03.038

Logesh Kumar, M., and Revathi, V. (2016). Metakaolin bottom ash blend geopolymer mortar - a feasibility study. Constr. Build. Mater. 114, 1-5. doi:10.1016/j.conbuildmat.2016.03.149

Luna-Galiano, Y., Leiva, C., Villegas, R., Arroyo, F., Vilches, L., and FernándezPereira, C. (2018). Carbon fiber waste incorporation in blast furnace slag geopolymer-composites. Mater. Lett. 233, 1-3. doi:10.1016/j.matlet.2018.08.099

Rovnaník, P. (2010). Effect of curing temperature on the development of hard structure of metakaolin-based geopolymer. Constr. Build. Mater. 24, 1176-1183. doi:10.1016/j.conbuildmat.2009.12.023

Saccani, A., Manzi, S., Lancellotti, I., and Lipparini, L. (2019). Composites obtained by recycling carbon fibre/epoxy composite wastes in building materials. Constr. Build. Mater. 204, 296-302. doi:10.1016/j.conbuildmat.2019.01.216

Saccani, A., Sandrolini, F., Andreola, F., Lancellotti, I., Barbieri, L., and Corradi, A. (2005). Influence of the pozzolanic fraction obtained from vitrified bottom ashes from MSWI on the properties of cementitiuos composites. Mater. Struct. 38, 367-371. doi:10.1007/BF02479303

Saccani, A., Sandrolini, F., Barbieri, L., and Lancellotti, I. (2001). Structural studies and electrical properties of re-cycled glasses from glass and incinerator wastes. J. Mater. Sci. 36, 2173-2177. doi:10.1023/A:1017539932421

Sha, D., Pan, B., and Sun, Y. (2020). A novel raw material for geopolymers: coalbased synthetic natural gas slag. J. Clean. Prod. 262, 121238. doi:10.1016/j. jclepro.2020.121238

Silva, R. V., de Brito, J., Lynn, C. J., and Dhir, R. K. (2017). Use of municipal solid waste incineration bottom ashes in alkali-activated materials, ceramics and granular applications: a review. Waste Manag. 68, 207-220. doi:10.1016/j. wasman.2017.06.043

Sun, Z., and Vollpracht, A. (2019). One year geopolymerisation of sodium silicate activated fly ash and metakaolin geopolymers. Cem. Concr. Comp. 95, 98-110. doi:10.1016/j.cemconcomp.2018.10.014

Tang, P., Florea, M., Spiesz, P., and Brouwers, H. (2016). Application of thermally activated municipal solid waste incineration (MSWI) bottom ash fines as binder substitute. Cem. Concr. Comp. 70, 194-205. doi:10.1016/j.cemconcomp.2016. 03.015

Uddin, F., and Shaikh, A. (2013). Review of mechanical properties of short fibre reinforced geopolymer composites. Constr. Build. Mater. 43, 37-49. doi:10. 1016/j.conbuildmat.

UNI 7699 (2005). Testing hardened concrete. Determination of water absorption at atmospheric pressure, Milano, Italy: Ente Nazionale Italiano di Unificazione.

Vilaplana, J. L., Baeza, F. J., Galao, O., Alcocel, E. G., Zornoza, E., and Garces, P. (2016). Mechanical properties of alkali activated blast furnace slag pastes reinforced with carbon fibers. Constr. Build. Mater. 116, 63-71. doi:10.1016/ j.conbuildmat.2016.04.066

Wang, Y., Zhang, S., Li, G., and Shi, X. (2019). Effects of alkali treated recycled carbon fiber on the strength and free drying shrinkage of cementitious mortar. J. Clean. Prod. 228, 1187-1195. doi:10.1016/j.jclepro.2019.04.295

Wongsa, A., Boonserm, K., Waisurasingha, C., Sata, V., and Chindaprasirt, P. (2017). Use of municipal solid waste incinerator (MSWI) bottom ash in high calcium fly ash geopolymer J. Clean. Prod. 148, 49-59. doi:10.1016/j.jclepro. 2017.01.147

Zhu, W., Chen, X., Struble, L. J., and Yang, E.-H. (2018). Characterization of calcium containing phases in alkali-activated municipal solid waste incineration bottom ash binder through chemical extraction and deconvoluted Fourier transform infrared spectra. J. Clean. Prod. 192 782-789. doi:10.1016/j.jclepro.2018.05.049

Conflict of Interest: The authors declare that the research was conducted in the absence of any commercial or financial relationships that could be construed as a potential conflict of interest.

Copyright (c) 2020 Manzi, Lancellotti, Masi and Saccani. This is an open-access article distributed under the terms of the Creative Commons Attribution License (CC $B Y)$. The use, distribution or reproduction in other forums is permitted, provided the original author(s) and the copyright owner(s) are credited and that the original publication in this journal is cited, in accordance with accepted academic practice. No use, distribution or reproduction is permitted which does not comply with these terms. 